\title{
Never a Better Time for Open Source
}

\author{
Matt Asay,
}

DOI: $\underline{10.5033 / \text { ifosslr.v2i2.48 }}$

\begin{abstract}
Matt Asay, senior vice president of business development at Strobe, takes stock of developments in the legal environment surrounding open source which have taken place in 2010.
\end{abstract}

\section{Keywords}

Law; information technology; Free and Open Source Software

\section{Info}

This item is part of the Tech Watch section of IFOSS L. Rev. For more information, please consult the relevant section policies statement.

If we needed any further confirmation that open source has gone mainstream, just look at the number of lawyers circling its skies. The European Legal Network, one of if not the main legal network, now boasts over 250 lawyers and of course in the last two years, spawned this journal.

No one bothers to sue the impoverished: now that open-source software is minting money for Google, IBM, Red Hat, and others, it has taken centre stage in the litigation front, through 2010.

While many of us would probably prefer to remain off the legal radar, the reality is that legal action is part and parcel with open source's importance in the industry. Bad as it is to be constantly fending off patent lawsuits, the opposite is even worse.

Why is open source so relevant to the technology industry today? Because we are in the midst of a tectonic shift in how software is delivered; a shift from value in the bits themselves to value in the services around the bits. Cloud computing, Software-as-a-Service, and open source each presents different faces on this trend. Small wonder, then, that Dresdner RCM Global Investors principal Walter Price, Jr. anticipates "a secular decline in tech spending," pointing the industry "to an environment where it will be difficult for [tech vendors] to keep revenues growing." ${ }^{1}$

As incumbent vendors struggle to remain relevant, one response has been to launch lawsuits to slow their obsolescence. Like the water-seekers in T.S. Eliot's epic poem "The Wasteland", who

1 http://online.barrons.com/article/SB50001424053111904502004575562243330821352.html 
find "no water but only rock," leaving them with with "red sullen faces [that] sneer and snarl."

And sue, apparently.

In 2010, Android was the most obvious recipient of the legal profession's attentions, with Apple, Microsoft, Oracle, and many others lining up to halt the open-source platform's rise or at least profit therefrom. Rather than sue Google directly, most of these parties preferred to sue different members of the Android ecosystem like HTC, the handset manufacturer.

While Google has not publicly commented on many of the suits, given that it is not directly named in them, Google did vigorously rebut Oracle's claims of patent infringement for the way Google uses Java in Android. Interestingly, its response was less about the law than about the politics and history of Oracle's contradictory and not-so-open approach to managing Java. ${ }^{2}$ In responding to Oracle's suit, Google attempted to rally the open-source community to its side:

"We are disappointed Oracle has chosen to attack both Google and the open-source Java community with this baseless lawsuit. The open-source Java community goes beyond any one corporation and works every day to make the web a better place. We will strongly defend open-source standards and will continue to work with the industry to develop the Android platform."

Good politics, but not necessarily sound legal doctrine.

Perhaps Google was hoping that public opinion could gain it some clarity in the dispute, given that the law increasingly does not. In 2008 many of us saw the Bilski case as a ray of hope, a sign that U.S. courts would invalidate decades of bad law that tried to shape intellectual property to mirror the world of physical property, with adverse effects. ${ }^{3}$ Since that time, however, no industry-wide decimation of the patent regime has occurred, either in the United States or in Europe, and it is looking doubtful that it ever will. The poor, and patents, are evidently always with us.

With this in mind, it strikes me that organisations like the Open Invention Network and other open-source friendly patent collectives will gain an increasing importance in the industry. Most of the upstarts giving established vendors fits lack significant patent portfolios, making a collective approach the only feasible manner of competing with the SAPs and Oracles of the world on somewhat equal footing.

I also believe that the open-source legal community needs to continue to lower the bar to adoption of and participation in open source. One current endeavour is Project Harmony, an attempt to systematise contributor agreements for open-source communities. Despite the opposition from some in the broad open-source community for such a project, it can do much to help would-be participants navigate the complexities of open source, similar to what the Open Source Initiative has done for normalising open-source licensing.

There has never been a better time for open-source software, and the increasing frequency of intellectual property claims against prominent users and developers of open source is one clear

2 http://www.scribd.com/doc/38782601/Google-Answer-to-Oracle-Java-lawsuit

3 http://www.reuters.com/article/idUSTRE49T7HI20081031 
sign of this. Open source increasingly fuels the growth of companies like Facebook and Twitter, while simultaneously challenging the standard operating procedures of our industry's venerable (and more and more vulnerable) incumbents. Game on.

\section{About the author}

Matt Asay is senior vice president of business development at Strobe, a startup that offers an open source framework for building mobile apps. He was formerly chief operating officer of Ubuntu commercial operation Canonical. With more than a decade spent in open source, Asay served as Alfreso's general manager for the Americas and vice president of business development, and he helped put Novell on its open-source track. Asay is an emeritus board member of the Open Source Initiative (OSI). His column, Open... and Shut, appears twice a week on The Register. 


\section{Licence and Attribution}

This paper was published in the International Free and Open Source Software Law

Review, Volume 2, Issue 2 (December 2010). It originally appeared online at http://www.ifosslr.org.

This article should be cited as follows:

Asay, Matt (2010) 'Never a Better Time for Open Source', IFOSS L. Rev., 2(2), pp 197 $-200$

DOI: $\underline{10.5033 / \text { ifosslr.v2i } 2.48}$

Copyright (C) 2010 Matt Asay.

This article is licensed under a Creative Commons UK (England and Wales) 2.0 licence, no derivative works, attribution, CC-BY-ND.

As a special exception, the author expressly permits faithful translations of the entire document into any language, provided that the resulting translation (which may include an attribution to the translator) is shared alike. This paragraph is part of the paper, and must be included when copying or translating the paper.

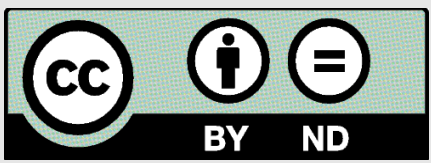

